\title{
Sarcopenia prevalence
}

\author{
M. U. Pérez-Zepeda • L. M. Gutiérrez-Robledo • V. E. Arango-Lopera
}

Received: 26 June 2012 / Accepted: 4 July 2012 / Published online: 1 August 2012

(C) International Osteoporosis Foundation and National Osteoporosis Foundation 2012

\section{Dear Editor,}

Regarding the recent report by Patil and colleagues about sarcopenia and osteopenia prevalence [1], we would like to address some methodological issues. It is stated that the prevalence of sarcopenia using the European Working Group on Sarcopenia in Older People (EWGSOP) is $0.9 \%$. This is grossly out of other frequencies reported using the same algorithm, which is over $30 \%$. The first report by Landi and colleagues showed a prevalence of $32.8 \%$ in a group of institutionalized elderly $(n=122)$, while our group reported $33.6 \%$ in an ambulatory sample of 70 years or older subjects $(n=345)[2,3]$. The first report included all the residents of the nursing home where the study was performed, while our study used a representative sample of Mexico City. However, the sample of Patil et al. was derived from an intervention study, in which neither the whole population $(n=9,370)$ nor a representative sample was used. Although an excellent sample of a study was aimed to have internal validity, external validity represented by prevalence could be misleading [4]. Nevertheless, other factors could contribute to different frequencies of sarcopenia, like those already pointed by the authors: lack of precise diagnostic criteria and unavailability of standard reference data to the components of the EWGSOP algorithm $[1,5]$.

\section{References}

1. Patil R, Uusi-Rasi K, Pasanen M, Kannus P, Karinkanta S, Sievänen H (2012) Sarcopenia and osteopenia among 70-80-year-old homedwelling Finnish women: prevalence and association with functional performance. Osteoporos Int. doi:10.1007/s00198-012-2046-2

2. Landi F, Liperoti R, Fusco D, Mastropaolo S, Quattrociocchi D, Proia A, Russo A, Bernabei R, Onder G (2011) Prevalence and risk factors of sarcopenia among nursing home older residents. J Gerontol A Biol Sci Med Sci 67(1):48-55

3. Arango-Lopera VE, Arroyo P, Gutiérrez-Robledo LM, PérezZepeda MU (2012) Prevalence of sarcopenia in Mexico City. European Geriatric Medicine 3:157-160

4. Kukull WA, Ganguli M (2012) Generalizability: the trees, the forest, and the low-hanging fruit. Neurology 78:1886-1891

5. Rosenberg IH (2011) Sarcopenia: origins and clinical relevance. Clin Geriatr Med 27:337-339

A reply to this comment is available at doi:10.1007/s00198-012-2092-9.

M. U. Pérez-Zepeda $(\bowtie) \cdot$ L. M. Gutiérrez-Robledo •

V. E. Arango-Lopera

Instituto Nacional de Geriatría,

Periférico Sur 2767 Colonia San Jerónimo Lídice,

Delegación Magdalena Contreras,

Mexico City, Mexico

e-mail: ulises.perez@salud.gob.mx 